\title{
Fundamentos filosóficos do Design: uma reflexão acerca de seus diferentes aspectos de abordagem
}

\author{
Philosophical foundations of Design: a reflection on its different \\ aspects of approach
}

Paula da Silva Hatadani, Paula Rodrigues Napo, Paula da Cruz Landim, Fausto Orsi Medola

Filosofia do Design; Positivismo; Subjetivismo

\begin{abstract}
Este artigo realiza uma revisão teórica sobre a influência do positivismo no Design e apresenta alguns paradigmas alternativos. Argumenta-se que novos alinhamentos epistemológicos possam ser a base para inovações nas formas de se pensar e fazer Design, especialmente diante dos desafios colocados na contemporaneidade. Para tal, foram elencadas as aproximações filosóficas do Design ao longo da história e apresentadas as alternativas epistemológicas propostas por Reyes (2010), Beccari et al (2017) e Najar (2019). Assim, propõe-se uma discussão sobre as possíveis consequências que cada uma destas diferentes perspectivas poderia resultar nos processos de Design.
\end{abstract}

Epistemology of Design; Positivism; Subjectivism

This article performs a theoretical review on the influence of positivism on Design and presents some alternative paradigms. It is argued that new epistemological alignments can be a basis for innovations in the ways of thinking and doing Design, especially in the face of the challenges faced today. To this end, they were listed as philosophical approaches to Design throughout history and places as epistemological alternatives proposed by Reyes (2010), Beccari et al (2017) and Najar (2019). Thus, we propose to discuss on the possible consequences that each of these different possibilities result in Design processes.

\section{Introdução}

Diversos autores têm enfatizado a importância de se pensar o Design como atividade projetual complexa, que pode ser definida tanto como processo quanto como resultado, e cujo principal objetivo é o de promover transformações sociais por meio da criatividade e da inovação (BONSIEPE, 2011; CARDOSO, 2004; LANDIM, 2010). Constata-se, porém, que, em grande parte, a pesquisa, o ensino e as práticas de Design ainda estão estreitamente ligados a uma perspectiva prática e objetivista, que culmina, constantemente, na predominância do fazer em detrimento do pensar (LANDIM, 2010), indicando um hiato para a discussão sobre novas perspectivas filosóficas na área.

Anais do $10^{\circ} \mathrm{CIDI}$ e $10^{\circ} \mathrm{CONGIC}$

Kelli C.A.S. Smythe, Rafael de Castro Andrade (orgs.) Sociedade Brasileira de Design da Informação - SBDI Curitiba | Brasil | 2021 Curitiba | Brazil | 2021 
O Design, ao ter construído seus fundamentos teóricos predominantemente a partir do positivismo - desde o seu surgimento enquanto formação profissional com a criação da Bauhaus e a Escola de Ulm, até o surgimento do Design Thinking, por exemplo - configurou uma prática projetual coerente com a ótica Comtiana. Como exemplo desta afirmação, pode-se citar a aplicação de métodos, a sistematização de processos criativos e a crença de que o desenvolvimento ocorre pelo incremento de produtos industriais (BURDEK, 2010; REYES, 2010; CRUZ et al., 2012; NAJAR, 2019).

À vista disso, e considerando que o Design carrega, até hoje, tanto na prática profissional quanto no âmbito da academia, a tradição deste ponto de vista, supõe-se relevante investigar possíveis paradigmas alternativos.

Tendo como ponto de partida este contexto e também as grandes crises e transformações de ordem social, econômica e ambiental pelas quais atravessam a humanidade na contemporaneidade, que indicam a urgência da adoção a novos paradigmas e valores sociais, esta pesquisa propõe realizar uma revisão histórica do Design, evidenciando seus alinhamentos epistemológicos em cada cenário ao longo do século XX. A partir dessas elucidações, parte-se para a revisão e discussão de algumas propostas alternativas pautadas no subjetivismo, sugeridas por Reyes (2010), Beccari et al. (2017) e Najar (2019).

\section{Fundamentos filosóficos do Design e a influência do positivismo}

\section{O positivismo}

O positivismo surgiu no século XIX e sua origem é creditada ao francês Auguste Comte (1798 1857). Em meio às mudanças e crises características deste período histórico da Europa como por exemplo, o crescimento desordenado das indústrias e das cidades e o avanço da desigualdade social -, Comte propôs criar uma sistematização dos pensamentos humanos, tendo quatro objetivos principais: evidenciar as leis lógicas do espírito humano; promover uma reforma geral na educação; promover o progresso nas diversas ciências; e reorganizar a sociedade em bases sólidas (CRUZ; PERASSI; VIEIRA, 2012).

A Lei dos Três Estados, formulada por Comte, sugeria que o desenvolvimento da humanidade passa por três estados históricos sucessivos: do estado teológico (ou fictício) para o estado metafísico (ou abstrato) para, por fim, chegar ao estado científico ou positivo. O primeiro: busca da natureza íntima dos fenômenos e suas causas, cujos créditos se davam a seres sobrenaturais. O segundo: um estágio intermediário, surgido com o início da filosofia, no qual não há mais espaço para as entidades sobrenaturais, que são substituídas pelo conceito de "forças abstratas". Por último, o estado científico caracteriza-se como aquele em que há uma restrição à descrição dos fenômenos naturais, fundamentada na observação e no trabalho empírico. A ciência neste último estágio seria, portanto, responsável por levar adiante a marcha para o progresso social (CRUZ; PERASSI; VIEIRA, 2012).

O pensamento positivista procura por leis gerais capazes de explicar o comportamento humano e a natureza por meio da quantificação, assim como enfatiza a rejeição da metafísica e 
de explicações dependentes de fenômenos subjetivos, tais como intenções e propósitos. A filosofia positivista nega tudo aquilo o que não pode ser acessado pela objetividade do raciocínio humano, não considerando qualquer especulação que ultrapasse a experiência, pois a convicção é de que somente os objetos da observação, e particularmente os da observação sensível e mensurável, merecem esta qualificação. Trata-se de uma postura fundamentada no paradigma de que a realidade está posta, cabendo ao sujeito desvelá-la por meio de métodos de observação dos fenômenos. Deste fato deriva a crença de que o conhecimento deve ser guiado pelo empirismo, sendo o pesquisador compreendido como sujeito dotado de neutralidade neste processo (NAJAR, 2019).

Assim, a sistematização dos conhecimentos humanos objetivos era a proposta positivista para todas ciências, que deveria ser aplicada a todas as atividades humanas - inclusive o Design.

\section{O nascimento do Design: breve panorama}

Até o século XVIII todos os produtos eram frutos do trabalho de uma só pessoa, o artífice ou artesão, que era responsável por todas as fases do processo de produção: desde o conceito, até a produção e entrega final do produto físico. Com a Revolução Industrial, de acordo com Cruz et. al (2012), o resultado foi a separação da conceituação e da produção de produtos, criando ofícios distintos.

Com isso, criou-se uma nova profissão, a do Designer, como resultado desta sociedade sedenta de inovações e com uma nova mentalidade científica, incorporada à atividade industrial e seus novos meios de produção (NAJAR, 2019).

O Positivismo se espalhou por todo o ambiente cultural do século XIX e, da mesma forma, a Revolução Industrial se viu igualmente sob a filosofia positivista. Os industriais da época, para validarem o aumento de seu poder social e ascensão empresarial, com os ideais de ordem e progresso, valeram-se da filosofia positivista, na procura por uma sociedade melhor, segundo Cruz et. al (2012)

Diante desta realidade, tem-se o surgimento da Escola de Artes e Ofícios na Alemanha, a Bauhaus. Escola estatal, fundada em 1919, em Weimar, que foi sucessivamente transferida para Dessau e Berlim, e, por fim, em 1933, foi fechada pelo governo nazista.

A Bauhaus foi pioneira no ensino de novas técnicas e recursos que até hoje são os elementos básicos da cultura visual e organizacional dos cursos de Design. "A filosofia de Comte e a esperança na indústria formaram a constituição filosófica do pensamento do Design frente à sua participação na sociedade " (CRUZ et al., 2012, p. 162).

A partir da década de 1990, o Design começou a se reposicionar devido às transformações de uma sociedade industrial e consumista. Neste contexto, Cardoso (2008) volta o seu olhar para o profissional de Design, uma vez que com o advento das novas tecnologias do final do século $X X$ e do século $X X I$, o mercado tende a reduzir proporcionalmente a exigência de algumas habilidades tradicionais, tais como saber desenhar ou fotografar. Todavia, segundo Cardoso (2008), é a capacidade de gerar soluções criativas e originais que faz com que o profissional designer se diferencie dos demais. Landim (2010) complementa: 
A produção do Design tem enfatizado o fazer. Mas só é possível fazer com coerência e crítica, se houver anteriormente o pensar, a articulação das ideias. Portanto o Design é antes de tudo um ato intelectual. Estamos pensando/refletindo o Design, ou estamos apenas fazendo Design?

(LANDIM, 2010, p.17)

Neste âmbito parece residir a essência da atividade de Design, ou seja, conceber informação visual com efetividade, aplicabilidade e de forma atraente, na produção de um ambiente informacional mais assertivo e significativo. Atualmente, num mundo cada vez mais complexo, é necessário um maior grau de sofisticação para decifrar a ordem velada na desordem aparente (CARDOSO, 2008).

A reflexão sobre o exercício da atividade do designer na atualidade é pertinente e muito amplo, levando-se em conta os diversos aspectos existentes em uma sociedade contemporânea instável e muitas vezes caótica.

\section{Design Thinking (DT): o início de uma mudança de paradigma}

O Design Thinking (DT) como abordagem de Design, tem evoluído pouco a pouco desde o final da década de 1960, tendo se apropriado de ferramentas e técnicas de áreas criativas, sociais e tecnológicas.

Uma década antes, 1950, Simon (1996) sugere as premissas de uma ciência do Design com base nos paradigmas dos processos cognitivos de problem-solving: "When we study the process of Design we discover that Design is problem solving. If you have a basic theory of problem solving then you are well on your way to a theory of Design" (SIMON, 1996, p. 344-345).

Lima et. al (2014) definem o DT como o "processo de inovação centrado no ser humano que enfatiza observação, colaboração (cocriação), rápido aprendizado, visualização de ideias, prototipagem rápida de conceitos e análise de negócio (próprio e do concorrente), que influencia inovação e estratégia de negócio“.

A origem do termo data de 1969, advinda dos estudos da ciência cognitiva, pelo engenheiro Herbert A. Simon, no livro The Science of The Artificial. O conceito foi definido e popularizado, na década seguinte, em 1970. Basicamente, o Design foi dissociado de sua fisicalidade e inicia o processo da criação de interações, segundo o llabs (2018)

Rittel (1972), foi considerado pioneiro em tentar definir a teoria do Design ao passo que se concentrava em métodos de Design. Contrariamente a seus antecessores, ele defendeu a importância da percepção e experiência humana ao longo do projeto. Assim, a Fenomenologia (a ciência da experiência), pela primeira vez foi apresentada ao Design de experiências.

A partir daí, nas décadas seguintes, vários profissionais e pesquisadores do Design e das áreas da engenharia, psicologia e arquitetura ampliaram seus trabalhos e pesquisas nesta área. Os Designers foram estudados a fim de verificar seus comportamentos e mentalidades.

Para Eysenck (2000), tais pesquisas foram realizadas com base nos enfoques positivistas e das ciências cognitivas, não se levando em conta aspectos subjetivos, sociais e ambientais e "a possibilidade de que aqueles Designers pensavam e resolviam problemas daquela forma, não 
porque aquele fosse uma espécie de DNA da cognição do Designer; mas antes, porque haviam sido formados por paradigmas que favoreciam tal pensamento" (NAJAR, 2019, p.151).

Segundo Brown (2010), o principal foco do DT são as pessoas. Um projeto de DT pressupõe levantamento sobre problemas reais das pessoas. Possui cinco fases: 1) Imersão; 2) Análise e Síntese dos dados coletados; 3) Ideação; 4) Prototipagem; 5) Validação/Implementação.

Pela premissa de ser centrada no ser humano, levando em conta as experiências subjetivas dos indivíduos e ao adotar critérios qualitativos e interpretativos na análise dos dados, a metodologia proposta pelo $\mathrm{DT}$, se mostra distante do paradigma positivista. O que promove uma ampliação dos espaços para reflexões mais filosóficas acerca de sua prática. (NAJAR, 2019)

Contudo, para Najar (2019), mesmo assim, o DT, apesar de adotar um discurso mais humanista, ainda é executado com base em metodologias, ferramentas padronizadas e na organização de etapas organizadas, o que remonta a características positivistas e cognitivistas. Destaca, assim, uma incongruência epistemológica, ao expor o conflito existente entre um Design empírico, que procura mensurar os resultados objetivamente e de forma neutra e, por outro lado, um Design que procura enxergar e apreender a realidade de uma ótica subjetiva e por meio de uma maior reflexão filosófica (NAJAR, 2019).

\section{Alternativas epistemológicas}

Os contrapontos apresentados ao positivismo, segundo os autores aqui elencados, teriam aproximações com o subjetivismo. A subjetividade é interpelada neste capítulo sob diferentes abordagens: Reyes (2010) apresenta a Fenomenologia da Imaginação como possível articuladora da dimensão criativa do Design; Najar (2019) propõe o Pós-estruturalismo para romper com a organização e as certezas buscadas pelo objetivismo; e Beccari et al. (2017) constroem uma proposta de organização dos aspectos filosóficos do Design por meio de seis eixos de reflexão que possuem uma perspectiva humanística.

O subjetivismo parte do princípio de que o sujeito é o centro do conhecimento, sendo que o lugar e os instrumentos de observação influenciam a experiência e dela fazem parte. Sob esta ótica, o pensamento do sujeito tem papel central sobre a sua experiência no mundo, por isso, a construção da verdade depende da posição do observador. A relatividade é um conceito chave da perspectiva subjetivista, que abraça a pesquisa qualitativa como método principal.

Alinhada a estes princípios, a Fenomenologia da Imaginação de Bachelard, segundo Reyes (2010), afirma que o sujeito não desvela o real, mas o constrói como uma realidade possível. Com isso, Bachelard propõe que se pense a realidade como resultado de uma criação, ou seja, como um artefato intelectual (REYES, 2010, p.104).

É na projeção do que está por vir que a força da imaginação criadora se efetiva. Para Bachelard, essa realidade construída seria sempre provisória, prestes a ser reconstruída, num processo complexo de verificação e retificação realizado pelo sujeito. O objeto, assim, nunca é totalmente desvelado, pois o conhecimento sobre ele é sempre aproximado, uma vez que 
é o resultado de construções racionais. É importante destacar, ainda, que neste processo de construção da realidade, o sujeito também constrói a si mesmo (REYES, 2010).

Bachelard apoia-se num método que apreende o descontínuo como interrupção do curso do raciocínio, pois alinha-se à perspectiva de que a horizontalidade, ou a linearidade, é uma ilusão. Ou seja, a aceitação desta descontinuidade é um princípio que estaria em total oposição ao pensamento positivista.

Reyes (2010) explica que, para Bachelard, a percepção está subordinada à imaginação, dando ao processo de imaginação, assim, status de "realidade" e não de "real". Aproximando ao âmbito do Design, o autor defende que a imaginação deve ser vista como operativa sobre o real, constituindo-se em uma ferramenta de projeto e não só de representação, pois isto reduziria a sua potência teórica e criativa.

Entretanto, Reyes (2010) não propõe uma radicalização epistemológica no âmbito do Design a partir da Fenomenologia da Imaginação, mas sim uma flexibilização em suas abordagens metodológicas. Partindo do princípio de que o processo de criação não é linear, sua proposta busca confirmar que é nos processos de tentativa e erro que a criação se efetiva. Essa opção metodológica, recuperaria, para a área de projeto em Design, uma perspectiva mais aberta e flexível do processo projetual.

O método aqui desenvolvido compreende a realidade como algo inapreensível na sua totalidade, afirmando que a apreensão do objeto de estudo é sempre aproximada e nunca completa. Não ser total não significa superficialidade. Ao contrário, esse método permite um processo de retificação, processo esse tão caro a Bachelard (REYES, 2010, p. 107).

Najar (2019) apresenta a adoção do Pós-estruturalismo como alternativa epistemológica para o Design. Assim como a Fenomenologia da imaginação, esta abordagem não considera o conhecimento humano como uma representação da realidade, mas sim, como um processo de significação. O sujeito é compreendido como ser relacional, comandado por estruturas inconscientes, e por isso, a concepção de um ser humano universal não existe. Além disso, a realidade para o pós-estruturalismo é retratada ao mesmo tempo em que é construída pelo sujeito, portanto, não está dada a priori, e por isso, não é possível compreender o conhecimento e a realidade como "neutros", "absolutos" ou "transparentes". Desta forma, o foco do Pós-estruturalismo são as variadas formas de experiências vivenciadas em diferentes contextos, por diferentes indivíduos.

Neste contexto, Najar (2019) afirma que o Design e os artefatos de Design não podem ser compreendidos isoladamente, mas somente em relação a outros elementos do sistema no qual estão inseridos. Por isso, é possível inferir que, sob esta ótica, um Designer não projeta artefatos, mas relações e inter-relações simbólicas. Ressalta-se, ainda, que tais inter-relações são compreendidas como mais importantes do que os elementos particulares.

Sob os métodos da perspectiva pós-estruturalista, os processos do Design poderiam ser criados e desconstruídos ao mesmo tempo em que ocorrem, gerando uma espécie de "desorganização" metodológica, de articulação entre caos e ordem. Tal "desorganização", 
argumenta Najar (2019), pode ser benéfica ao Design, ao passo em que permite toda ordem de conexões por meio da não-previsibilidade e da subversão da lógica organizadora. Quebras, rupturas e novas direções se tornariam a nova lógica metodológica.

Beccari et al. (2017) apresentam uma proposta de organização de aspectos filosóficos para o Design por meio de seis eixos de reflexão que visam propor subsídios para uma Filosofia do Design. Ainda que não seja objetivo dos autores apresentar uma alternativa epistemológica para o Design em contraponto ao objetivismo, compreende-se que acabam por fazê-lo, ao mencionar que o Design é encarado, em seu trabalho, sob uma perspectiva "humanística".

Segundo os autores, as perspectivas humanísticas às quais fazem menção partem dos seguintes pressupostos: 1) não são "técnicas", isto é, não se apresentam como meio para algum fim definido, tampouco como base para alguma prática definida; 2) encaram o Design de maneira ampla, como uma atividade criativa que pode assumir formas variadas em diferentes culturas, lugares e momentos históricos, não se reduzindo, portanto, a uma atividade profissional específica, inserida em um mercado; e 3 ) encaram a filosofia (tanto quanto o Design) como uma forma de criação e expressão humanas, de modo que não se atribui ao olhar filosófico a capacidade de revelar qualquer tipo de verdade transcendental. Segundo os autores, estudos nestas direções têm-se mostrado como uma tendência crescente desde início dos anos 2000, promovendo o esfumaçamento de modelos teóricos totalizantes anteriores (Beccari et al., 2017).

Cada um dos seis eixos da proposta elaborada por Beccari et al. (2017) trabalha com uma definição diferente do Design, mas podem ser compreendidas, de um modo geral, como complementares. Tais eixos foram organizados tomando como base a tradicional subdivisão da filosofia em cinco ramos principais e adaptados minimamente para a conjuntura do Design: lógica, estética, ética, epistemologia e ontologia. Sendo assim, os seis eixos são: 1) Design e linguagem: o Design como um articulador de significados; 2) Design e sensibilidades: o Design como um articulador de afetos; 3) Design e valores: questões ligadas à relação entre orientações projetuais e orientações éticas ou às relações entre tecnologia, estilo e moralidade; 4) Design e conhecimento: o Design como uma forma de saber/conhecer; 5) Design e realidade: o Design como um articulador de realidades; e 6) Design e cultura: o Design como produto sociocultural (BECCARI et al., 2017).

Em resumo, existem dois pressupostos evidentes da perspectiva subjetivista de Beccari et al. (2017): o primeiro, de que há sempre um filtro subjacente a toda e qualquer reflexão ou proposição que se queira enunciar, que pode-se compreender como oposição à visão de que a realidade existe e pode ser compreendida em sua universalidade; e segundo, que não há, dentre as perspectivas possíveis, nenhuma que possa ser tomada de modo totalizante e universal - o que há é a possibilidade de cruzamento e diálogo entre visões de mundo distintas, de modo a ampliar a complexidade de uma reflexão filosófica. 


\section{Discussão}

A revisão sobre o contexto do surgimento do Design esclareceu as causas da aproximação de seus fundamentos com a epistemologia positivista. Esta aproximação, decorrente do movimento social coletivo em favor da construção da sociedade industrial, ocorreu em um cenário cujo "espírito do tempo" valorizava e buscava pelo progresso, pela ordem e pela inovação, em favor do desenvolvimento de uma sociedade melhor. A filosofia Comtinana, tendo influenciado todo o ambiente social e cultural do século XIX, prometia ser o caminho para esta inovação. Desta forma, entende-se que o surgimento do Design foi consequência do advento de novos meios de fabricação, mas o seu estabelecimento se concretizou exatamente por causa da sua união com os valores da sociedade da época, que reforçaram e validaram a sua atividade.

O Positivismo influenciou e ainda influencia o Design, embora correntes teóricas surgidas no final do século $X X$, como o Design Thinking, tenham buscado essa desvinculação. Algumas evidências dessa afirmação podem ser observadas nos seguintes fatos: de maneira geral, muitas vezes o Design ainda se utiliza do discurso positivista para se legitimar enquanto ciência; há uma evidente valorização da utilização de ferramentas padronizadas em suas práticas; alguns dos métodos de Design ainda são organizados em etapas lineares, embora atualmente não sejam tão reconhecidos; e, especialmente, na percepção de que ainda está embutida na área, ainda que muitas vezes de forma implícita, a busca pelo "progresso" por meio do desenvolvimento material e tecnológico, que se desdobraria, então, em progresso cultural e econômico.

Assim, foram encontrados três autores cujas publicações evidenciam um movimento de consciência na busca por uma conformidade entre epistemologia e metodologias, métodos e práticas em Design: Reyes (2010), Najar (2019) e Beccari et al. (2017), como possíveis alternativas ao paradigma positivista para o Design, porque propõem uma ruptura com a lógica objetivista.

Reyes (2010) apresenta a Fenomenologia da Imaginação de Bachelard. Sua justificativa para tal escolha é que o pensamento bachelardeano propõe que a realidade é construída por meio da criação de "artefatos intelectuais", sendo este um processo não-linear, aberto a constantes verificações e ajustamentos. Esta característica mutável e complexa desta perspectiva teórica abriria espaço para se pensar em metodologias que não prezassem por uma visão horizontal de raciocínio, mas sim por um acolhimento à descontinuidade em seus processos. Outra importante questão é que, da mesma forma, a Fenomenologia da Imaginação não compreende o tempo no sentido de linearidade temporal, e por isso, não haveria como se pensar o progresso como evolução ou ascensão. Diferentemente da ótica positivista, o progresso para Bachelard consistia no aprimoramento do próprio sujeito.

Já Najar (2019) defende que o Pós-estruturalismo pode ser a ponte para a inovação epistemológica no Design, já que se configura como uma abertura para uma visão de mundo subjetivista, ao mesmo tempo em que a adoção de seus métodos traduziriam uma escolha radicalmente oposta ao positivismo, já que operam no caminho contrário da lógica organizadora. É certo afirmar que para que esta perspectiva seja adotada pelo Design é 
necessário entender que a mesma não oferece certezas ou qualquer previsibilidade. Contudo, é este o objetivo de Najar. Para ele, a pesquisa pós-estruturalista em Design pode ser arriscada, desafiadora e insubordinada, tendo sempre caráter filosófico e exploratório.

A proposta de organização de aspectos filosóficos sugerida por Beccari et al. (2017) indica possibilidades de abordagens epistemológicas alternativas, embora os autores não apresentem o tema diretamente desta maneira. Verificou-se que a concepção dos autores prevê uma filosofia ancorada essencialmente na subjetividade e, em suas palavras, numa perspectiva humanística. Isto se explica, primeiramente, pois os autores não defendem uma visão unificadora de Design, pretendem promover uma multiplicidade de pontos de vista e acolher, inclusive, as divergências de diversas áreas do conhecimento. Quanto mais olhares houver sobre um objeto, mais completo será o conceito sobre ele - indicando uma visão não absoluta, mas mais ponderada e mais complexa sobre a teoria, os métodos e as práticas em Design. Em segundo lugar, porque a essência da proposta não é a de legitimar o conhecimento verdadeiro e real, mas sim, de favorecer reflexões atentas às visões complementares ou até mesmo conflitantes, que proporcionariam um aumento da criatividade e das possibilidades de inovação em Design.

As três propostas possuem em comum a procura por uma inversão na ótica tradicionalista de conceber o Design, levando em consideração os desafios postos pelo novo panorama social, histórico e cultural em que este está inserido, a pós-modernidade. Argumentam que a lógica dos tempos atuais, muito ligada à subjetividade, não admite mais a compreensão integral do real, a objetividade científica, a linearidade e o progresso como valores. Sobre este último, pode-se dizer que a noção de "progresso", compreendido com a ótica positivista da Revolução Industrial, também estaria obsoleto, pois já se sabe que pode trazer consigo malefícios sociais e ambientais, além de outras consequências não desejadas.

Neste sentido, os autores apontam como necessária, de forma mais ou menos evidente, a ressignificação da noção de "evolução". Além disso, os autores levantam questionamentos e críticas a respeito dos métodos positivistas, que, segundo eles, reproduziriam e reconstruiriam uma visão de mundo demasiadamente pragmática. Assim, argumentam que seria necessário romper com este paradigma para atingir novos patamares no Design, sendo que a base que daria sustentação a esta disrupção seria uma nova perspectiva filosófica e epistemológica, escolhida a partir de valores alinhados à subjetividade, à complexidade e à significação.

Importante salientar que não se pretendeu, neste artigo, apresentar todas as alternativas epistemológicas existentes, nem realizar uma reflexão final sobre as que foram apresentadas. Acredita-se que estas ponderações possam fomentar a curiosidade pela temática e incentivar novas pesquisas na área, ampliando o debate sobre como se pode pensar e fazer Design nos dias atuais.

Além disso, é relevante enfatizar que os estudos aqui apresentados não pretenderam invalidar ou menosprezar o paradigma epistemológico positivista, predominante até este momento da história do Design. Ao contrário, acredita-se que o conhecimento destes fatos contribui para uma maior consciência e autonomia para designers e pesquisadores de Design, 
já que pensar e avaliar as próprias práticas é um processo contínuo e significativo de auto reflexão e aprimoramento, que separa a mera reprodução mecânica da práxis.

\section{Considerações finais}

Acredita-se que o debate acerca das abordagens filosóficas do Design é apenas a ponta do iceberg. É necessário ampliá-lo em prol de uma reflexão próspera, na qual os processos e métodos estejam em discussão, à disposição dos designers e que estes desenvolvam a autonomia para o alinhamento consciente entre uma ou outra orientação epistemológica ou metodologia.

Vale salientar que ao trazer a luz esta discussão, abre-se uma oportunidade para uma construção maior dos saberes da área da Filosofia do Design. De acordo com Cruz et. al (2012), uma aproximação entre o Design e a Filosofia se mostra de grande valia, pois para se entender o Design, é considerável compreender os princípios filosóficos que ajudam a definir o que ele mesmo é.

Outra reflexão está relacionada ao ensino de Design nas universidades. Teóricos e docentes buscam cada vez mais ajustar as teorias do Design com as práticas mercadológicas, portanto, tal discussão inserida no espaço acadêmico terá consequências no mercado. Landim (2010), ressalta a importância deste alinhamento e que apenas nas mãos de profissionais críticos e responsáveis é que o Design pode ser um poderoso agente de transformações.

Para que isso possa acontecer, são necessários modelos e práticas que tenham por base outro paradigma, ou seja, que concebam os conhecimentos e os processos de formação como espaço conceitual no qual se constroem novos saberes como resultados sempre contraditórios de vários processos históricos, culturais, sociais, etc.

A história do Design deve ter como prioridade não a transmissão de dogmas que restrinjam a atuação do Designer mas a abertura para novas possibilidades que ampliem seus horizontes, sugerindo a partir da riqueza de exemplos do passado, formas criativas e conscientes de se proceder no presente.

Enquanto questões acerca dos domínios, fronteiras e perspectivas futuras do Design fizerem parte do cotidiano dos designers, esse debate permanece ativo e necessário de ser realizado constantemente.

Logo, conclui-se que ampliando-se a inserção do Design na cena do debate filosófico contemporâneo, muitos serão os desafios postos pela experiência intelectual atrelada ao Design (Beccari et. al., 2017). Consideram-se que os novos questionamentos e reflexões tornam-se criativos quando as visões em jogo entrarem em contato com outras visões, e assim, acabarão por expandir seu repertório interpretativo. 


\section{Referências}

Beccari, M.; Portugal, D. B.; Padovani, S. (2017). Seis eixos para uma filosofia do Design. Estudos em Design, Rio de Janeiro, v. 25, n. 1, p. 13-32, 2017. Disponível em: https://estudosemDesign.emnuvens.com.br/Design/article/view/432. Acesso em 07 jul. 2020

Bonsiepe, G. (2011). Design, cultura e sociedade. São Paulo: Blucher.

Brown, T. (2010). Design Thinking: Uma metodologia poderosa para decretar o fim das velhas ideias. São Paulo: Elsevier Editora.

Bürdek, B.E. (2010) Design: História, teoria e prática do Design de produtos. São Paulo: Blucher.

Capra, F., Luisi, P; L. (2014). A visão sistêmica da vida: uma concepção unificada e suas implicações filosóficas, políticas, sócias e econômicas. São Paulo: Cultrix.

Cardoso, R. (2004). Uma introdução à história do Design. São Paulo: Edgar Blücher, 2004.

Cardoso, R. (2008). O Design gráfico e sua história. Revista artes visuais, cultura e criação. Rio de Janeiro, 2008 - academia.edu. Disponivel em:

https://docente.ifrn.edu.br/carlosdias/informatica/programacao-visual/o-design-grafico-e-suahistoria Acesso em 19 jul. de 2020

Coelho, L .A. L. (organizador) (2008). Conceitos-chave em Design. Rio de Janeiro: Ed. PUCRio. Novas Idéias.

Costa, J. C. (1950) Augusto Comte e as origens do Positivismo. Revista de História, São Paulo, v. 3, n. 1, p. 363-382, 07 set. 1950. Fluxo Contínuo. Disponível em:

http://www.revistas.usp.br/revhistoria/article/view/34860. Acesso em 10 jul. 2020

Cruz, T. A.; Perassi, R. L.; Vieira, M. L. (2012). O Positivismo e a sua influência sobre o Design. Projetica, Londrina, v. 3, n. 1, p. 158-167, jul. 2012. Semestral. Disponível em: http://www.uel.br/revistas/uel/index.php/projetica/article/view/9959. Acesso em 19 jul. 2020

Eysenck, M. W. (2000). Psychology: A student's handbook. New York: Psychology Press.

llabs (2018). A origem do Design Thinking e quem fez isso acontecer. Disponível em: https://www.ilabs.services/post/2018/06/26/a-origem-do-Design-thinking-e-quem-fez-issoacontecer. Acesso em 17 jul. de 2020.

Landim, P. C. (2010). Design, Empresa, Sociedade. São Paulo: Cultura Acadêmica.

Lima, A. M.; Alves, A. T.; Costa, A. J.; Sales, E. O. (2014). Metodologia Design thinking no projeto de software para mobilidade urbana: relato de aplicação. AtoZ: novas práticas em informação e conhecimento, Curitiba, v. 3, n. 2, p. 128-138, jul./dez. 2014. Disponível em: <http://www.atoz.ufpr.br>. Acesso em 17 jul. 2020

Najar, Rodrigo. Perspectivas epistemológicas e design: uma abordagem pós-estruturalista. Estudos em Design, Rio de Janeiro, v. 27, n. 1, p. 149-160, 2019. Semestral. Disponível em: https://estudosemdesign.emnuvens.com.br/design/article/view/678. Acesso em: 03 jun. 2020.

Reyes, P. (2010). Tudo o que não invento é falso: por uma epistemologia da imaginação criadora no Design. Strategic Design Research Journal. São Leopoldo, p. 102-108. set.2010.Disponível em: http://revistas.unisinos.br/index.php/sdrj/article/view/4793. Acesso em 20 jul. 2020 
Rittel, H.W.J. On the Planning Crisis: Systems Analysis of the First and Second Generations.

Bedriftsøkonomen, n. 8, out. 1972.

Simon, H. A (1996). The sciences of the artificial. MIT press, 1996. História das Artes: Bauhaus.

Disponivel em: https://www.historiadasartes.com/nomundo/arte-seculo-20/bauhaus/ Acesso em 17 jul. 2020

\section{Sobre o(a/s) autor(a/es)}

Paula da Silva Hatadani, Me., UNESP, Brasil <paulahatadani@yahoo.com.br>

Paula Rodrigues Napo, Me., UNESP, Brasil <paulanapo@gmail.com.br>

Paula da Cruz Landim, Dra., UNESP, Brasil < paula.cruz-landim@unesp.br>

Fausto Orsi Medola, Dr., UNESP, Brasil < fausto.medola@unesp.br> 